\title{
Implication of Low Temperature and Sonication on Electrocrystallization Mechanism of Cu Thin Films: A Kinetics and Structural Correlation
}

\author{
Archana Mallik*, Bankim Chandra Ray \\ Electrometallurgy and Corrosion Laboratory, Department of Metallurgical and Materials Engineering, \\ National Institute of Technology, Rourkela, 769008, India
}

Received: April 16, 2012; Revised: November 24, 2012

\begin{abstract}
The effect of an ultrasonic environment during electrodeposition of copper on graphite at various electrolyte temperatures of $25,20,15,10$ and $5{ }^{\circ} \mathrm{C}$ is reported in this investigation. Resulting $\mathrm{Cu}$ deposits formed by potentiostatic deposition were characterized by electrochemical methods, scanning electron microscopy and atomic force microscopy. It was found that in presence of ultrasound the deposition kinetics was mainly dominated by the charge transfer. Copper nucleated according to 3D instantaneous mechanisms for all temperature ranges. The extent of nucleation was found to be increased at low temperatures. Diffusion coefficients and nuclei population density were calculated for each temperature range. Sonicated deposits with good surface coverage were found to consist of spherical copper agglomerates of nanosized particles.
\end{abstract}

Keywords: electrocrystallization, thin film, copper, low-temperature, sonication, crystal nucleation kinetics

\section{Introduction}

It is scarcely surprising that, as the temperature is varied within the wide range available, the properties of all materials undergo very considerable modifications. Hence there are fundamental, analytical and technological reasons for the need of extending this temperature range for venturing into the relatively unexplored science ${ }^{1,2}$. Coupling ultrasound with the depositing bath may introduce a second level of metastability with a wide variation of effects on the deposit morphology and properties ${ }^{3-6}$, resulting primarily from acoustic cavitaion: the formation, growth, and implosive collapse of microscopic bubbles in liquids ${ }^{7-10}$. Electrodeposition in presence of ultrasound may have effects on the deposits in terms of appearance, adherence, grain morphology and habitats. To cite few are, reduction in grain size ${ }^{11}$, change in grain orientation with wave orientation ${ }^{12}$, particle agglomeration and increased dispersion ${ }^{13-15}$, brighter surface ${ }^{16}$, reduction in residual stress and hence good adhesion ${ }^{12,17}$ have been observed at constant frequency and power output. While with varying frequency and intensity, inconsistent fluctuations in the deposit behavior were also cited in the literature ${ }^{12,18}$. Authors have certainly enlisted the interesting beneficial synergistic effects. However, the findings are incompetent without proper information on the mechanism and kinetics of the phase formation. Electrochemistry at low temperature will likely be a diffusion controlled system whereas insonation may make a transformation of the plain system to a more complex one by introducing convective mass flow ${ }^{12,19}$.

*e-mail: archananitrkl@gmail.com
The present investigation focuses on the effects of temperature and ultrasound on the kinetics of $\mathrm{Cu}$ redox couple from the sulfate bath by using cyclic voltammetry, chronoamperometry and morphological analysis to understand the nucleation mechanisms.

\section{Material and Methods}

Graphite electrodes (Asbury, USA) of $0.25 \mathrm{~cm}^{2}$ surface area were used to electrodeposit the copper films. Experiments were carried out onto single graphite electrodes for different sections of study. The bath composition was $6.35 \mathrm{gL}^{-1} \mathrm{Cu}^{2+}+60 \mathrm{gL}^{-1} \mathrm{H}_{2} \mathrm{SO}_{4}$. Chemicals used were as purchased (Merck Chemical Co.). Double-distilled water was used throughout the experimentation for preparation of solution and other purposes. The electrochemical cell was a conventional three-electrode configuration, with a $5 \mathrm{~cm}$ long counter electrode of $\mathrm{Pt}$ rod $\left(3.5 \mathrm{~cm}^{2}\right)$ and a $\mathrm{Ag} / \mathrm{AgCl}$ reference electrode ( $3 \mathrm{M} \mathrm{KCl}$, Eco chemie). Regular glass beakers of $500 \mathrm{~mL}$ volume were used as the electrolytic cells for experiments with ultrasound. The sonication cell was having a water jacket with a temperature below the experimented electrolyte temperature. The arrangement was made to maintain a constant temperature during the sonication experiment. A high-density ultrasonic probe (Sonics \& Materials, VCF1500) equipped with a $12.5 \mathrm{~mm}$ diameter titanium oscillator (horn), operating at $20 \mathrm{kHz}$ with a $20 \%$ (1500 Watt max.) power output was used for ultrasonic irradiation. The working electrode was facing to the ultrasonic horn (Figure 1). Depositions were carried out at temperatures of $25^{\circ} \mathrm{C}, 20^{\circ} \mathrm{C}, 15^{\circ} \mathrm{C}, 10^{\circ} \mathrm{C}$ and $5{ }^{\circ} \mathrm{C}$. 


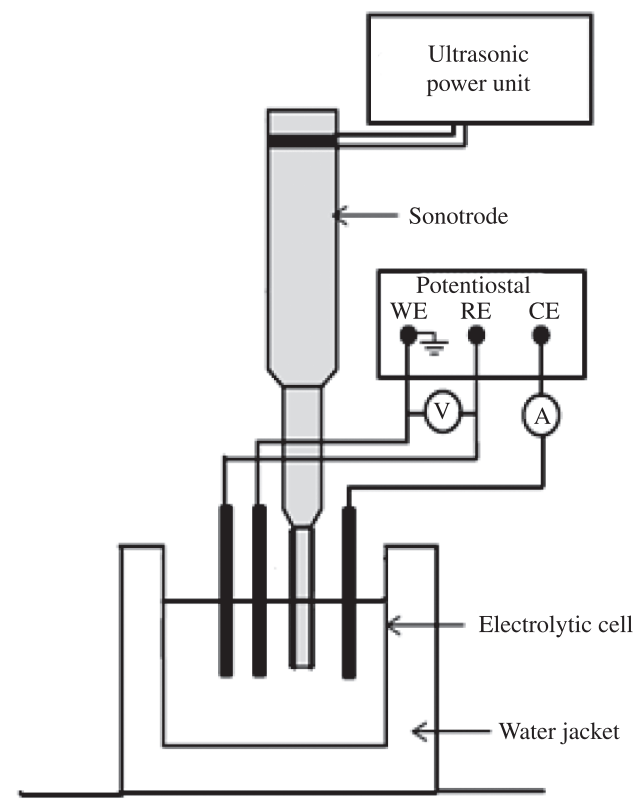

Figure 1. A schematic view of the experimental set up for the electroplating of copper using a beaker as an electrolytic cell.

Electrochemical measurements were conducted using a Potentiostat/Galvanostat (Eco Chemie Netherlands, Autolab PGSTAT 12) interfaced with a PC controlled with GPES software. A potential of $-300 \mathrm{mV}$ was selected for the deposition. The surface morphology comparisons were obtained using scanning electron microscopy (SEM, JEOL 6480 LV with Oxford data system) and atomic force microscopy (AFM, SPMLab-programmed Veeco diInnova) in the contact mode with a conducting $\mathrm{P}(\mathrm{n})$-doped silicon tip.

\section{Results and Discussion}

\subsection{Cyclic voltammetry}

Figure 2 shows two voltammograms recorded during copper electrodeposition onto graphite substrates in (a) absence (silent) and (b) presence of ultrasound at a scan rate of $10 \mathrm{mV} . \mathrm{s}^{-1}$. The scanning ranges are $-0.6 \mathrm{~V}$ to $+0.6 \mathrm{~V}$ and $-0.6 \mathrm{~V}$ to $+1 \mathrm{~V}$ for silent and sonication conditions respectively to ensure complete dissolution of the deposited mass in both the conditions.

The silent scan has both cathodic and anodic peaks, while the insonated CV has only the dissolution peak. During the sonicated cathodic scan, the reduction of copper ions has an onset potential near $+50 \mathrm{mV} v s$. Ag/AgCl. Figure 2 also shows that, in anodic scan the anodic peak current for stripping or dissolution of copper on graphite is increased by 4-fold under insonation (Figure $2 b$ ) as compared to silent conditions (Figure 2a). Stirring of solution by the acoustic streaming during the sono-voltammetric scan may have hindered the depletion of electroactive species in the vicinity of the electrodes during deposition which has resulted the increase in cathodic and anodic currents. Moreover, the anodic peak potential also shifted to more positive values

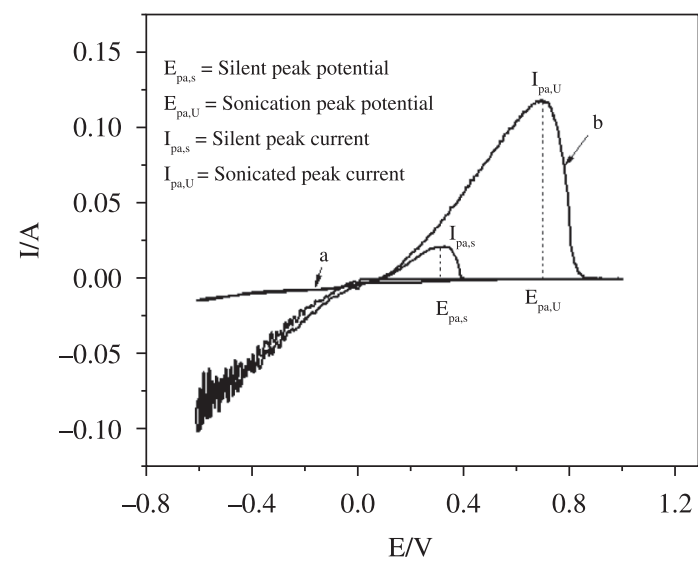

Figure 2. Cyclic voltammetry of copper redox reaction from a solution of $6.35 \mathrm{gL}^{-1} \mathrm{Cu}(\mathrm{II})$ and $60 \mathrm{gL}^{-1}$ sulfuric acid at $25^{\circ} \mathrm{C}$ in (a) silent and (b) sonication conditions.

under ultrasound $(20 \mathrm{kHz}), E_{\mathrm{pa}, \mathrm{U}}=+693 \mathrm{mV}$ compared with $E_{\mathrm{pa}, \mathrm{S}}=+344 \mathrm{mV}$ vs. $\mathrm{Ag} / \mathrm{AgCl}$ in silent condition. So a $\Delta E$ of approximately $+349 \mathrm{mV}$ was found under sonication and this displacement of the anodic peak potential is most likely due to the Ohmic drop in the solution. And this may be manifested by the sonication effect on the rate of mass transport and other associated effects in the electrochemical bath $^{20}$.

In order to identify the kinetics and rate-controlling steps of the electrodeposition of copper, the investigation is now focused on the effects of low temperature and ultrasound (Figure $3 \mathrm{a}$ ) on the variations of the voltammograms. All sono-voltammograms tends to have area of stability at high potentials i.e. a limiting current, which depends on the magnitude of the diffusion layer thickness ${ }^{21,22}$, expressed as:

$I_{\lim }=n F A D C^{*} / \delta$

where $I_{\text {lim }}$ is the limiting current (A), $n$ is the number of electrons transferred during the electrochemical process, $F$ is the Faraday constant $\left(96,500 \mathrm{C} \cdot \mathrm{mol}^{-1}\right), A$ is the electrode area $\left(\mathrm{cm}^{2}\right), D$ is the diffusion coefficient $\left(\mathrm{cm}^{2} \cdot \mathrm{s}^{-1}\right), C^{*}$ is the concentration of the species in the bulk solution $\left(\mathrm{mol} . \mathrm{cm}^{-3}\right)$ and $\delta$ is the diffusion layer thickness $(\mathrm{cm})$. Furthermore the limiting current value can be used to calculate the mass transfer co-efficient $k_{d}$, from the formula, $k d=\frac{I \text { lim }}{n F C}$, which characterizes the mass transport conditions from and/or towards electrode surface and, therefore, denotes a local measurement of the hydrodynamic conditions. The quantity varies from 5.9-6.54 $\times 10^{-3}$ with increase in temperature. Furthermore inside the cathodic zone $(E<0 \mathrm{~V})$ of voltammograms, a crossover on the cathodic branches was observed during the reverse potential scan which in turn indicates the deposition of copper through a nucleation and growth phenomena. The potential crossovers are present at the anodic potential region.

Apart from the phase kinetic characterization, the cross over potential can be related to the equilibrium potential, in this case $C u^{2+}(a q) / C u(s)$ and this equilibrium 


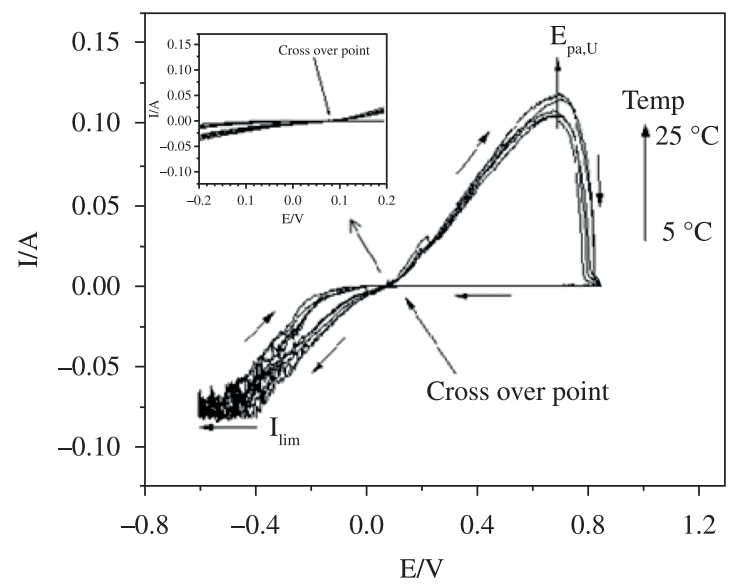

(a)

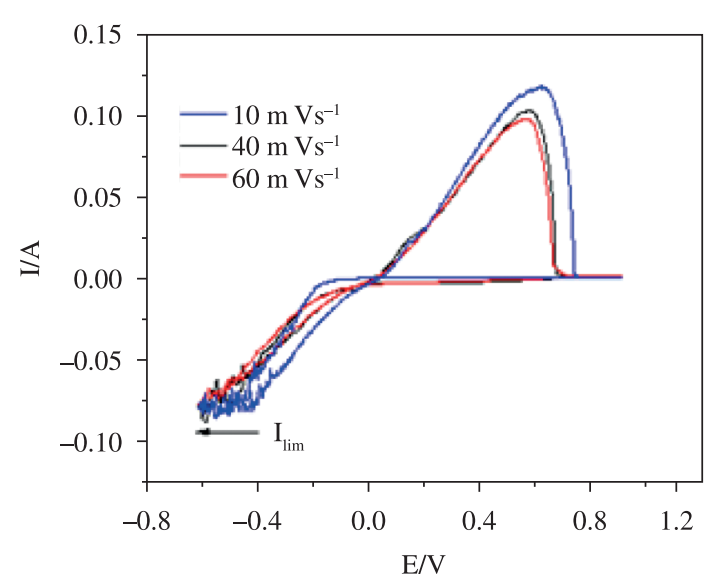

(b)

Figure 3. a) Cyclic voltammetry of copper redox reaction from a solution of $6.35 \mathrm{gL}^{-1} \mathrm{Cu}(\mathrm{II})$ and $60 \mathrm{gL}^{-1}$ sulfuric acid at different temperatures in sonication condition. b) Cyclic voltammograms for graphite electrodes in $6.35 \mathrm{gL}^{-1} \mathrm{Cu}(\mathrm{II})$ and $60 \mathrm{gL}^{-1}$ sulfuric acid at various sweep rates: $10 \mathrm{mVs}^{-1}, 40 \mathrm{mVs}^{-1}, 60 \mathrm{mVs}^{-1}$, at electrolyte temperature of $25^{\circ} \mathrm{C}$ in sonication condition.

potential in sonication has turned out to be independent of deposition temperature. The CV scans have well-resolved anodic peaks without any cathodic maxima. The absence of cathodic peaks for the insonated working electrodes may indicate a charge transport control reaction system. Stirring of solution by the acoustic streaming during the sono-voltammetric scan may have hindered the depletion of electroactive species in the vicinity of the electrodes during deposition which has caused the above effect. Further to supplement the observation, a set of voltammetric study were done with different scanning rates ${ }^{23}$. The influence of the potential scan rate $(v)$ on the $\mathrm{Cu}$ deposition at $5{ }^{\circ} \mathrm{C}$ is shown in Figure $3 b$. The scans reveal that with increase in scanning rate a decrease in peak height $\left(\mathrm{I}_{\mathrm{paU}}\right)$ was observed in contrary to the conventional increase in peak values. The unusual negative peak shift with increasing scan rate, the positive potential crossovers and absence of cathodic peaks may signify well availability of the reducing species at the electrode/electrolyte interphase, and, therefore may imply charge (or interfacial) control kinetics.

To analyze the deposition efficiency of the process (the total coulomb of charge consumed during deposition, $Q$ c, charge consumed during dissolution, $Q a$ ), the charges due to the cathodic and anodic processes are to be obtained from integration of the cathodic and anodic branches of the $I-E$ curves, respectively. Figure 4 shows plot of the $Q \mathrm{a} / Q \mathrm{c}$ ratio as a function of temperature for $\mathrm{Cu}$ deposition from solutions with sonication The $Q \mathrm{a} / Q \mathrm{c}$ ratio reached a value of 1 as temperature dips further indicating the anodically dissolution of cu deposition during the cathodic sweep potential. Since all the deposited $\mathrm{Cu}$ has got dissolve by Faradic reaction (not by ablation), the deposits should have good adherence with the substrate.

\subsection{Nucleation and growth analysis}

The nucleation phenomenon corresponds to the initial stage of copper electro-formation. It can be considered as the most critical stage of growth for definition of the final film

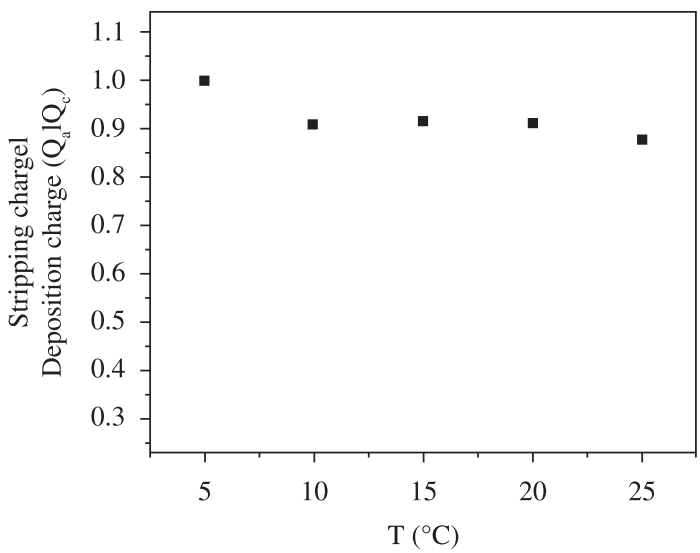

Figure 4. Stripping charge/deposition charge $Q_{a} / Q_{c}$ ) for sonicated deposits as a function of deposition temperature.

properties. The most widely used technique to capture and quantify the kinetics is a single step constant over voltage scan, chronoamperometry (ca). Based on the cathodic zone of the $\mathrm{CV}$ experimentation the reduction potential, $E_{\mathrm{c}}=-300 \mathrm{mV}$, was chosen. The effect of temperature on $i(t)$ curves were recorded during sonication copper formation.

Two-Point Golay-Savitzky normalization sono-chronoamperometry transients are shown in Figure 5. In presence of ultrasound and being emitted from a horn probe at a $5 \mathrm{~mm}$ distance from the working electrode, sonication was found to have random fluctuation in the observed current. The indiscriminate current variation results are similar to that of our previous work on the mechanism of nucleation in presence of ultrasound ${ }^{24}$. These current fluctuations are because of the continuous phase formation consisting of batches of sequential nucleation and growth cycles, the first being the primary nucleation and the rest are secondary nucleation on the existing primary nuclei due to crystal fragmentation. In each nucleation loop, the 
current peak is followed by a decreasing part of the transient, which corresponds to the current limited by the diffusion of $\mathrm{Cu}$ (II) species. The crystallographic misfit between the graphite and $\mathrm{Cu}$ atoms may favor a 3D nucleation and growth behavior, since the surface of vitreous carbon consists of randomly oriented $\mathrm{sp}^{2}$ carbon atoms, while copper atoms require ordered cryastallization in face-centered cubic geometry. Hence the Scharifker and Hills (SH) model was considered first in order to characterize the nucleation process $^{25}$. The slope of $\log$ (current density) vs $\log$ (time) varied from 0.3 to 0.6 , which indicates instantaneous phase appearance (as shown in Figure 6 for primary nucleation loop). Hence by applying the kinetics model we derived

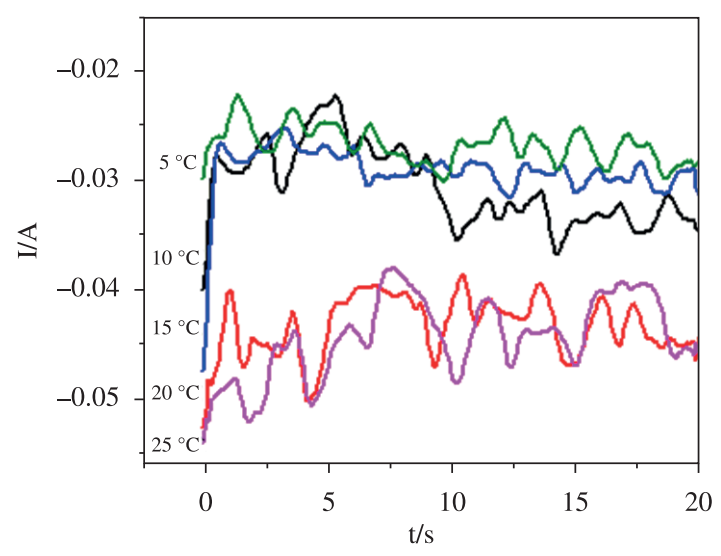

Figure 5. Chronoamperograms of sonicated copper deposits as a function of temperature.

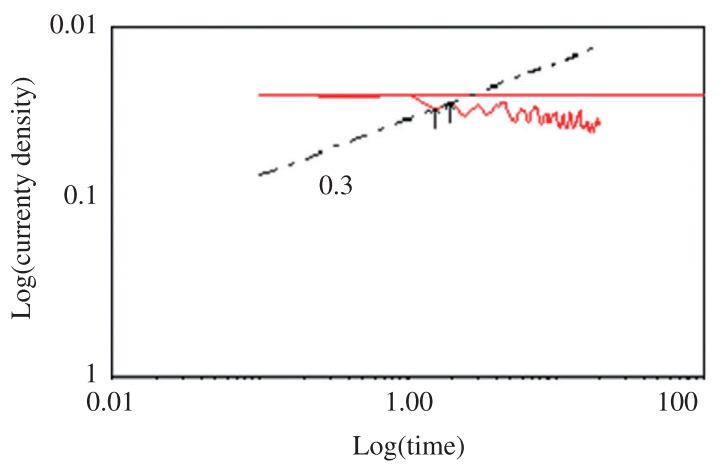

Figure 6. $\log ($ current density) vs $\log ($ time $)$ plot for sonicated $\mathrm{Cu}$ electrodeposition at $-300 \mathrm{~V}$ for 20 seconds. a 3D instantaneous mode of nucleation. A quantitative comparison of the temperature effect on the cavitation phenomena is represented in Table 1. The calculated nuclei number density $(N)$ and diffusion coefficient $(D)$ of the primary nucleation is taken into consideration as secondary nucleation would add some obvious data. Furthermore at high temperatures the fluctuations of these current was decreased. The variations of this mechanism with temperature can be explained on the basis of applied ultrasound intensity and the effects associated there. The authors have reported an increase of ultrasonic intensity of $134 \mathrm{~W} \mathrm{~cm}^{-2}$ to $177 \mathrm{~W} \mathrm{~cm}^{-2}$ as the temperature decreased from $25{ }^{\circ} \mathrm{C}$ to $5{ }^{\circ} \mathrm{C}^{[26]}$. In agreement with other reported happenings, the current spikes are found to be increased with increasing ultrasound intensity (here with decreasing temperature $)^{27,28}$. Hence the cavitation process becomes more violent at low temperatures. As a result possibly there will be intense crystal fragmentation and localized supersaturation at reducing temperatures. Consequently the films may have better surface coverage and finer grain depositions, as both the effects of increased level of supersaturation and crystal fragmentation will trigger primary and secondary nucleation respectively. This possibility is better comprehended in the next section of morphological analysis. Now comparing the cathodic charges generated in the due process, there wasn't any regular variation in the quantity. This can be explained by a combination of increased number of intense nucleation cycles, rapid random changes in the surface ion concentration and ablation of material at the electrode surface.

Figure 7 shows the SEM micrographs of the sono-electrodeposited thin films. The original morphology of the particles is approximately spherical with the diameter varying between $400 \mathrm{~nm}$ and $1 \mu \mathrm{m}$. It also seems that each particle is composed of a series of small particles (in the range of 30-50 $\mathrm{nm}$.) which can't grow separately and agglomerated to each other to form particles which are larger in size. Investigating on the surface coverage, sonoelectrochemically deposited films have good surface coverage. A nearly absolute coverage of the surface is achieved at $5{ }^{\circ} \mathrm{C}$. In case of a complete coverage of the surface, the electrodeposition of $\mathrm{Cu}$ may follow two different mechanisms ${ }^{29}$. Firstly, the deposition occurs on the bare graphite surface and the formation of first $\mathrm{Cu}$ nuclei. At the initial stage, $\mathrm{Cu}$ is deposited preferentially on the surface steps and on the defects of graphite. Afterward, the nuclei population density increases and the $\mathrm{Cu}$ deposit expands on

Table 1. Kinetic parameters of copper deposition in presence of ultrasound.

\begin{tabular}{cccc}
\hline & \multicolumn{2}{c}{ Kinetic parameters } & \multicolumn{2}{c}{$\begin{array}{c}\text { Charge consumed } \\
\text { (C) }\end{array}$} \\
\cline { 2 - 4 } Temp. $\left({ }^{\circ} \mathbf{C}\right)$ & $\mathbf{1 0}^{-4} D\left(\mathbf{c m}^{\left.\mathbf{2} . \mathbf{s}^{-1}\right)}\right.$ & $N\left(\mathbf{c m}^{-2}\right)$ & Sonication \\
\hline 25 & 8.7 & $5.10 \times 10^{6}$ & 0.538 \\
20 & 3.5 & $8.70 \times 10^{6}$ & 0.584 \\
15 & 1.95 & $1.70 \times 10^{6}$ & 0.611 \\
10 & 1.8 & $1.57 \times 10^{6}$ & 0.867 \\
5 & 1.3 & $3.50 \times 10^{6}$ & 0.887 \\
\hline
\end{tabular}


the totality of the surface. Secondly, a continuous deposition of $\mathrm{Cu}$ occurs on the freshly deposited $\mathrm{Cu}$ particles. Likewise these processes results in smoother uniform surface. Such control of the $\mathrm{Cu}$ particles distribution on vitreous graphite is only feasible if there is a continuous mass (ions) supply to the electrode/electrolyte interface (double layer). Hence the two path-ways are quite possible from a depositing bath where there is continuous stirring, extreme level of supersaturation (due to both temperature and sonication), possibility of secondary nucleation and the surface activation. However, the continuous surface cleaning (ablation) effect under insonation may rule out both the mechanisms and thus creating a zone of intricacy for uninterrupted instantaneous $\mathrm{Cu}$ phase nucleation and distribution. Now the nucleation path way followed in the due process can be explained from the data presented in Table 1. The percentage of primary nuclei in sonicated condition has lead to a surface coverage of $60 \%$, rest of surface occupancy could have been contributed by secondary nucleation. Hence insonation would have induced a nucleation mechanism which is combinations of the above two mechanism either occurring sequentially or simultaneously to form a superior deposit in terms of grain size, shape and distribution. Accordingly the best morphology with fine particles and good distributions was obtained for the deposit at $5{ }^{\circ} \mathrm{C}$ temperature. The surface profile and critical grain information are performed by phase mode $\left(-90^{\circ}\right.$ to $\left.+90^{\circ}\right)$ AFM studies (Figure 8$)$. The appearance of the deposits is similar to that of obtained by SEM experiments. Phase imaging goes beyond the simple topographical mapping to detect variations in composition, adhesion, friction, viscoelasticity, and numerous other properties. Here we coupled the phase mode micrographs

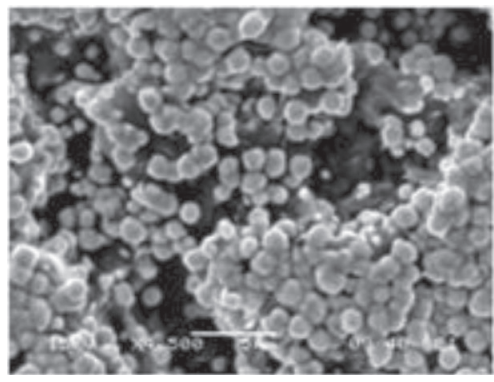

(a)

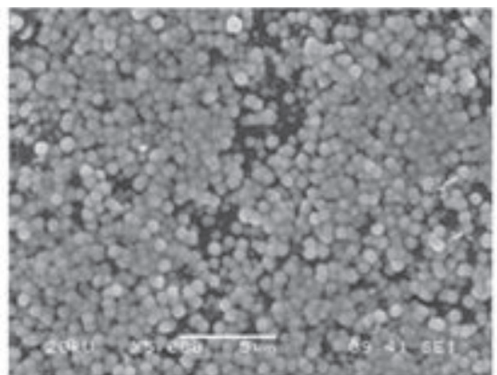

(b)

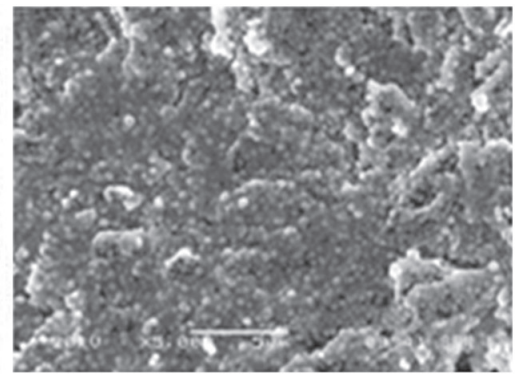

(c)

Figure 7. SEM micrographs of sonicated copper deposits at (a) $25^{\circ} \mathrm{C}$, (b) $15^{\circ} \mathrm{C}$ and (c) $5{ }^{\circ} \mathrm{C}$.

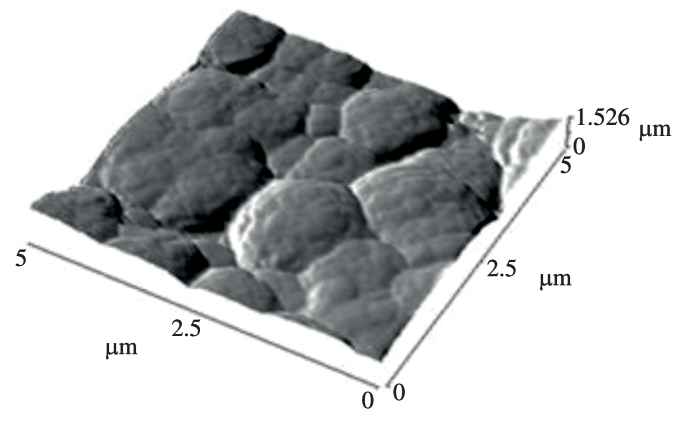

(a)

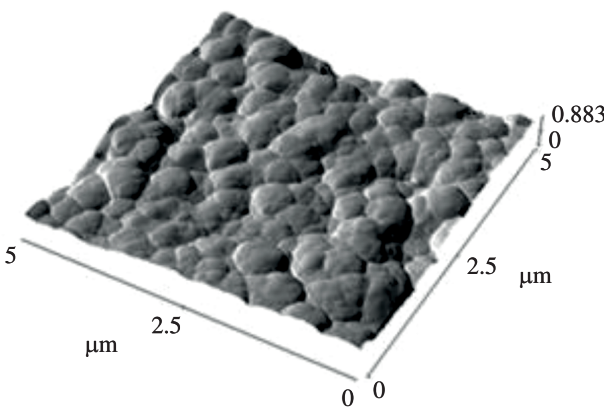

(c)

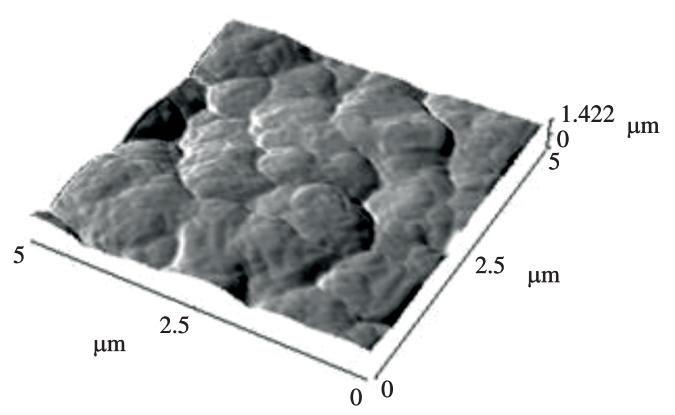

(b)

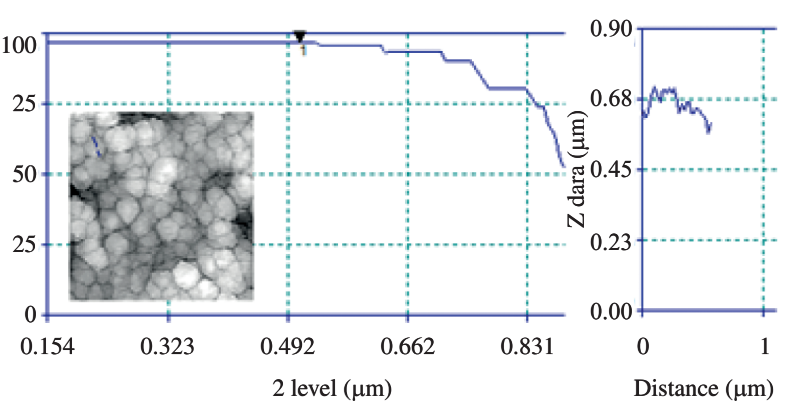

(d)

Figure 8. AFM phase micrographs of sonicated copper deposits at $25^{\circ} \mathrm{C}$, (b) $15^{\circ} \mathrm{C}$, (c) $5{ }^{\circ} \mathrm{C}$ and (d) $2 \mathrm{D}$ micrograph with calculated $\mathrm{BR}$ and height profile at $5{ }^{\circ} \mathrm{C}$. 
Table 2. AFM analysis parameters of sonicated copper deposits at different bath temperatures.

\begin{tabular}{cccccccc}
\hline \multirow{2}{*}{ Temperature $\left({ }^{\circ} \mathbf{C}\right)$} & \multicolumn{2}{c}{$\mathbf{R}_{\mathbf{a}}(\mathbf{n m})$} & \multicolumn{2}{c}{ Critical dimension $(\boldsymbol{\mu m})$} & \multicolumn{2}{c}{ Z level $(\mathbf{9 5 \%}$ BR) $(\mathbf{n m})$} \\
\cline { 2 - 8 } & Whole & Single & Whole & Single & Whole & Single \\
\hline 25 & 248 & 89 & 0.680 & 0.116 & 593 & 861 \\
15 & 194 & 51 & 0.500 & 0.103 & 382 & 582 \\
5 & 90 & 30 & 0.390 & 0.060 & 316 & 439 \\
\hline
\end{tabular}

with the $\mathrm{Z}$ height instead of phase angle to visualize the surface uniformities in terms of their properties as well as their profile. The aggregation of fine particles to form the big spherical clusters can better be clarified from the figures. Except the cluster boundaries the inter-cluster regions are in phase, which means the surface is free of discontinuities in terms of contaminants and preferential growth (dendritic growth). Further a single particle scan for the deposition at $5{ }^{\circ} \mathrm{C}$ (Figure 8d) has been performed for a detailed study of the surface texture. The single particle of $360 \mathrm{~nm}$ size was found to be a coalescence of large number of small particles (of 40-60 nm size) with average roughness ( $\mathrm{R}_{\mathrm{a}}$ ) of $30 \mathrm{~nm}$. Bearing ratio (BR) analysis shows that, $96.5 \%$ of the total particle height is above $439 \mathrm{~nm}$ and only $2 \%$ above $800 \mathrm{~nm}$ which results a $\mathrm{R}_{\mathrm{a}}$ of $90 \mathrm{~nm}$ for the whole surface. The definition of bearing ratio is the percentage of total data appearing above the selected $\mathrm{Z}$ level, hence higher the $\mathrm{BR}$ for the minimum $\mathrm{Z}$ level will be an analysis of smooth surface. Average roughness factor, $\mathrm{Z}$ level corresponding to $95 \% \mathrm{BR}$, critical dimension of bigger as well as the aggregating small particles for all deposition surfaces are presented in Table 2 . $\mathrm{R}_{\mathrm{a}}$ varies from $248 \mathrm{~nm}$ to $90 \mathrm{~nm}$ as the deposition temperature decreases. The table confirms the deposition at $5{ }^{\circ} \mathrm{C}$ to be of the highest surface finish. These observations may affect the state and intensity of depositing residual stresses and hence the de-lamination/adhesion characteristics of the deposited films onto the substrate ${ }^{30}$.

\section{Conclusions}

Correlating the morphological investigations (by SEM and AFM) with cyclic voltammetry and chronoamperometry, the mechanism and kinetics of ultrasound assisted by

\section{References}

1. McClintock PVE, Meredith DJ and Wigmore JK. Matter at Low Temperatures. Glasgow, London: Blackie \& Sons Limited; 1984.

2. Wildgoose GG, Giovanelli D, Lawrence NS and Compton RG. High temperature electrochemistry: A review. Electroanalysis. 2004; 16:421-433. http://dx.doi.org/10.1002/ elan.200302875

3. Doktycz SJ and Suslick KS. Interparticle Collisions Driven by Ultrasound. Science. 1990; 2:1067-1069. http://dx.doi. org/10.1126/science. 2309118

4. McCausland LJ, Cains PW and Martin PD. Use the power of sonocrystallization for improved properties. Chemical Engineering Progress. 2001; 97:56-61.

5. Walker R. Ultrasound and electroplating. Chemistry in Britain. 1990; 26:251-254. low temperature copper elctrocrystallization has been tried to be portrayed in this investigation. The motive of decreasing temperature in presence of ultrasound while electrodepositing copper from a simple sulfate bath was to favor the nucleation. A positive anodic peak shift was observed for insonicated CVs. The redox process in sonication condition was mainly charge transfer controlled. The deposition efficiency of the system was found to be good, which could be due to the absence of simultaneous undesired cathodic reactions and good adherence of the deposits to the substrate. Copper nucleated according to 3D instantaneous mechanisms for all temperature ranges. The extent of nucleation was found to be increased at low temperatures. The addition of sonication has further assisted the nucleation process by stimulating the biphasic nucleation sequence i.e. primary nucleation due to the extreme high level of localized supersaturation at low temperatures and secondary nucleation by breaking the existing primary nuclei. The spherical copper grains were found to consist of nanometer sized agglomerates. However, the simple logic presented in the present study is in fact based on a complex mass transport issue which takes into account all the types of mass transportation including migration, diffusion and convection. Hence, whether the proposed mechanisms are the correct path-way for the discharge of the reacting species will remain unclear until investigations are tallied for the depositions down to one monolayer.

\section{Acknowledgements}

The authors would like to thank the National Institute of Technology (NIT), Rourkela for providing the necessary financial and infrastructural supports.

6. Lorimer JP and Mason TJ. Sonoelectrochemisry. The application of ultrasound in electroplating. Electrochemistry (formerly Denki Kagaku). 1999; 67:924-930.

7. Suslick KS. Ultrasound: Its Chemical, Physical, and Biological Effects. New York: Wiley VCH; 1988.

8. Suslick KS. The chemical effects of ultrasound. Scientific American. 1989; 260:80-86. http://dx.doi.org/10.1038/ scientificamerican0289-80

9. Suslick KS, Cline RE and Hammerton DA. The sonochemical hotspot. Journal of American Chemical Society. 1986; 108:56415642. http://dx.doi.org/10.1021/ja00278a055

10. Suslick KS and Flint EB. Sonoluminescence of Non-Aqueous Liquids. Nature, 1987; 330:553-555. PMid:3683572. http:// dx.doi.org/10.1038/330553a0

11. Floate S, Hyde M and Compton RG. Electrochemical and AFM studies of the electrodeposition of cobalt on glassy carbon: an analysis of the effect of ultrasound. Journal of Electroanalytical 
Chemistry. 2002; 523:49-63. http://dx.doi.org/10.1016/S00220728(02)00709-X

12. Mallik A and Ray BC. Morphological study of electrodeposited copper under the influence of ultrasound and low temperature. Thin Solid Films. 2009; 517:6612-6616. http://dx.doi. org/10.1016/j.tsf.2009.04.054

13. Touyeras F, Hihn JY, Bourgoin X, Jacques B, Hallez L and Branger V. Effects of ultrasonic irradiation on the properties of coatings obtained by electroless plating and electro plating. Ultrasonics Sonochemistry. 2005; 12:13-19. PMid:15474947. http://dx.doi.org/10.1016/j.ultsonch.2004.06.002

14. Ghasemi S, Mousavi MF, Shamsipur M and Karami H. Sonochemical-assisted synthesis of nano-structured lead dioxide. Ultrasonics Sonochemistry. 2008; 15:448455. PMid:17644461. http://dx.doi.org/10.1016/j. ultsonch.2007.05.006

15. Mancier V, Daltin A.-L. and Leclercq D. Synthesis and characterization of copper oxide (I) nanoparticles produced by pulsed sonoelectrochemistry. Ultrasonics Sonochemistry. 2008; 15:157-163. PMid:17462940. http:// dx.doi.org/10.1016/j.ultsonch.2007.02.007

16. Walker CT and Walker R. Effect of ultrasonic agitation on some properties of electrodeposits. Electrodeposition and Surfacte Treatment. 1973; 1:457-569. http://dx.doi.org/10.1016/03009416(73)90029-1

17. Ohsaka T, Isaka M, Hirano $\mathrm{K}$ and Ohishi T. Effect of ultrasound sonication on electroplating of iridium. Ultrasonics Sonochemistry. 2008; 15:283-288. PMid:18164231.

18. Touyeras F, Hihn JY, Doche ML and Roizard X. Effect of ultrasound sonication on electroplating of iridium. Ultrasonics Sonochemistry. 2001; 8:285-288. http://dx.doi.org/10.1016/ S1350-4177(01)00090-6

19. Banks CE and Compton RG. Ultrasonically Enhanced Voltammetric Analysis and Applications: An Overview. Electroanalysis. 2003; 15:329-346. http://dx.doi.org/10.1002/ elan.200390040

20. Pollet BG and Phull SS. Recent research developments in electrochemistry. India: Transworld Research Network Publisher; 2001.

21. Cooper EL and Coury LA. Mass Transport in Sonovoltammetry with Evidence of Hydrodynamic Modulation from Ultrasound.
Journal of Electrochemical Society. 1998; 145:1994-1999. http://dx.doi.org/10.1149/1.1838588

22. Lorimer JP, Pollet B, Phull SS, Mason TJ, Walton DJ and Geissler U. The effect of ultrasonic frequency and intensity upon limiting currents at rotating disc and stationary electrodes. Electrochimical Acta. 1996; 41:2737-2741. http://dx.doi. org/10.1016/0013-4686(96)00130-2

23. Bard J and Faulkner LR. Electrochemical methods: Fundamentals and applications. John Wiley and Sons; 2001.

24. Mallik A, Bankoti A and Ray BC. A Study on the Modification of Conventional Electrochemical Crystallization under Sonication: The Phenomena of Secondary Nucleation. Electrochemical and Solid-State Letters. 2009; 12:F46. http:// dx.doi.org/10.1149/1.3243916

25. Scharifker B and Hills G. Theoretical and experimental studies of multiple nucleation. Electrochimica Acta. 1983; 28:879-889. http://dx.doi.org/10.1016/0013-4686(83)85163-9

26. Mallik A and Ray B. C. An analysis of the temperatureinduced supersaturation effects on structure and properties of sono-electrodeposited copper thin films. Surface and Coating Technology. 2011; 206:1947-1954. http://dx.doi.org/10.1016/j. surfcoat.2011.09.066

27. Del Campo FJ, Neudeck A, Compton RG and Marken F. Low-temperature sonoelectrochemical processes: Part 1. Mass transport and cavitation effects of $20 \mathrm{kHz}$ ultrasound in liquid ammonia. Journal of Electroanalytical Chemistry. 1999; 477:71-78. http://dx.doi.org/10.1016/S00220728(99)00391-5

28. Hardcastle JL, Ball JC, Hong Q, Marken F, Compton RG, Bull $\mathrm{SD}$ et al. Sonoelectrochemical and sonochemical effects of cavitation: correlation with interfacial cavitation induced by 20 kHz ultrasound. Ultrasonics Sonochemistry. 2000; 7:7-14. http://dx.doi.org/10.1016/S1350-4177(99)00026-7

29. Ghodbane O, Rou'e L and B'elanger D. Copper electrodeposition on pyrolytic graphite electrodes: Effect of the copper salt on the electrodeposition process. Electrochimica Acta. 2007; 52:5843-5855. http://dx.doi.org/10.1016/j. electacta.2007.03.009

30. Mallik A and Ray BC. Residual stress and nano-mechanical properties of sono-electrodeposited $\mathrm{Cu}$ films. Surface Engineering. 2011; 27:551-556. http://dx.doi.org/10.1179/17 43294411Y.0000000011 